Original Article

\title{
ASSESSING COSMECEUTICALS PROPERTIES OF SOME MACROFUNGI FOR IMPROVED SKINCARE
}

\author{
AKASH SARASWAT'1 , PURVI MATHUR¹, DOYELI SANYAL1*
}

1TERI-Deakin Nano Biotechnology Centre, Sustainable Agriculture Division, The Energy and Resources Institute, New Delhi 110003, India Email: doyeli.sanyal@teri.res.in

Received: 14 Oct 2019, Revised and Accepted: 10 Dec 2019

\begin{abstract}
Objective: This study has investigated cosmeceutical properties namely, antibacterial, sun protection factor and total phenolics contents of some selected macrofungi. The studies were conducted on five reference cultures collected from Indian type culture collection center (IMTEC, Chandigarh, India) and five isolates collected from TERI-Deakin Nano Biotechnology Centre facility at TERI Gram, Gurugram, India.

Methods: The cosmeceutical properties of the crude extracts from selected macrofungi were analyzed using standard bioassay techniques. Antibacterial activity was analyzed against Staphylococcus epidermidis, Escherichia coli, Micrococcus luteus, Bacillus megaterium, Pseudomonas aeruginosa, Staphylococcus aureus, and Acinetobacter baumannii using Agar well diffusion method. The sun protection factor was estimated and calculated using the Mansur equation. Free radical scavenging activity using DPPH was performed to assess the antioxidant activity of the extracts.
\end{abstract}

Results: Ethyl acetate extracts of the broth from $P$. florida and TERI-G1 cultures showed a broad-spectrum antibacterial activity against $S$. epidermidis, E. coli, M. luteus and B. megaterium. Ethyl acetate extracts of the broth from TERI-G3 showed the highest SPF activity of 34.02 at $200 \mu$ g. $\mathrm{ml}^{-1}$ concentration. Ethyl acetate extract of the broth from $F$. velutipes, $P$. florida, $P$. ostreatus, and TERI-G1 showed comparable antioxidant activity of $66.86 \%, 79.51 \%, 82.02 \%$, and $69.58 \%$ respectively when compared to ascorbic acid (85.83\%) and quercetin (83.09\%) taken as positive control in the study and their total phenolic contents were found to be 6.93, 43.68, 20.88 and 13.77 Gallic acid equivalent (GAE) per gram. The minimal inhibitory concentration of F. velutipes, P. florida, P. ostreatus, and TERI-G1 was found to be $3552.89 \mu \mathrm{g} . \mathrm{ml}^{-1}, 1250 \mu \mathrm{g}$. $\mathrm{ml}^{-1}, 2418.9 \mu \mathrm{g}$. $\mathrm{ml}^{-1}$ and 3219 $\mu$ g. $\mathrm{ml}^{-1}$ respectively.

Conclusion: The work is in progress to identify and characterize TERI-G1and TERI G3 cultures. Further studies on the anti-inflammatory, antityrosinase, elastase inhibition properties of the cultures will be assessed to identify potential cosmeceutical active ingredients with promising applications in cosmeceutical products.

Keywords: Chemical analysis, Microbiology, Spectroscopy, Macrofungi, bioassay studies

(C) 2020 The Authors. Published by Innovare Academic Sciences Pvt Ltd. This is an open-access article under the CC BY license (http://creativecommons.org/licenses/by/4.0/) DOI: http://dx.doi.org/10.22159/ijpps.2020v12i2.36074. Journal homepage: https://innovareacademics.in/journals/index.php/ijpps

\section{INTRODUCTION}

Presently, there is increasing consumer demand for cosmetics that incorporate organic and natural ingredients as a result of which the cosmeceutical division of the personal care industry is rapidly thriving [1]. Cosmeceuticals are products that comprise creams, lotions, and ointments and have both cosmetic and therapeutic effects due to the presence of bioactive ingredients which enhances skin health [2]. Recently macrofungi have attracted a lot of attention as an interesting source of unique bioactive. These contain substances like carotenoids, resveratrol, omega fatty acids, ceramides, etc [3] which makes them a potent candidate for use in the cosmetic industry. They are easy to grow and maintain and their extracted secondary metabolites can be used as enhanced analogs with minimum side-effects. These macrofungi have been well documented as to the source of polyphenolic, phenolics, polysaccharides, terpenoids, selenium, vitamins and volatile organic compounds. Many of these compounds have been associated with excellent antioxidant, anti-inflammatory, anti-bacterial, anti-viral, anti-aging, anti-wrinkle, skin renewal, skin whitening and moisturizing effects [4-6]. Macrofungi like Reishi (Ganoderma lucidum), Shiitake (Lentinula edodes), Maitake (Grifola frondosa), cauliflower mushroom (Sparassis latifolia), Fu Ling (Wolfiporia extensa), etc are popularly used in facial creams and serums in East Asian countries including Korea, Japan and China [7-9]. Tinder fungus (Fomes fomentarius), oyster mushroom (Pleurotus ostreatus), elm oyster mushroom (Hypsizygus ulmarius), Portobello mushroom (Agaricus bisporus) prevail more in the Western region [10-12]

These macrofungi also show interesting anti-microbial activities Lentinula edodes is very efficient against both gram-positive and gram-negative bacteria. Ganoderma, Lepista and Boletus species also show similar properties [13]. These macrofungi contain phenolic compounds that safeguard against viruses, bacteria, insects, and UV light [14].

Many well-known cosmetic brands nowadays use extracts of macrofungi in their products. For instance, the popular product range Aveeno Positively Ageless by Johnson and Johnson contains extract of Ganoderma lucidum and Lentinula edodes. Another brand, Vitamega cosmetics uses the extract of Agaricus subrufescens in their shampoo and moisturizing cream range. Earthherbs L. L. C. uses the extract of Siberian Chaga mushroom (Inonotus obliquus) in their antioxidant rejuvenating cream [15]

The present work is focused on exploring cosmeceutical properties namely; antibacterial, SPF, antioxidant activities and phenolics content of few selected identified (Pleurotus species, Flammulina species), and uncharacterized mushrooms collected from the TDNBC (TERI-Deakin Nano Biotechnology Centre) facility at TERI Gram, Gurugram, India.

\section{MATERIALS AND METHODS}

\section{Reagents}

All the reagents and chemicals used in the experiments were of analytical grade. Culture media (Nutrient Agar, Nutrient Broth, Potato Dextrose broth, Potato Dextrose Agar, Mueller Hinton agar no. 2) were collected from HiMedia Laboratories. Solvents (methanol, ethyl acetate, ethanol) and chemicals (Ascorbic acid, 1,1-Diphenyl-2-picrylhydrazyl (DPPH) Quercetin, Folin-Ciocalteu reagent, gallic acid) were purchased from Sigma Chemical Co., USA. Milli-Q water used in the studies has been obtained from Milli-Q® Integral by Merck. 


\section{Apparatus}

$1000 \mathrm{ml}$ Erlenmeyer flask, Buchner funnel assembly, rotary vacuum evaporator, UV visible spectrophotometer (SHIMADZU, UV 2450) were used in the study.

\section{Microbial culture}

Mushroom cultures namely, Flammulina velutipes (MTCC-543), Pleurotus florida (MTCC-9194), Pleurotus ostreatus (MTCC-1801, 1802) and Pleurotus sajor caju (MTCC-141) and bacterial cultures for antimicrobial studies namely, Staphylococcus epidermidis (MTCC-3615), Escherichia coli (MTCC-443), Micrococcus luteus (MTCC-106), Bacillus megaterium (MTCC-453), Pseudomonas aeruginosa (MTCC-424), Staphylococcus aureus (MTCC-1144) and Acinetobacter baumannii (MTCC-1425) were collected from Microbial Type Culture Collection and Gene Bank (MTCC), CSIR-Institute of Microbial Technology, Chandigarh, India. The fungal cultures were maintained in Potato Dextrose Agar plates at $28^{\circ} \mathrm{C}$. The bacterial cultures were maintained in Nutrient Agar plates at $28^{\circ} \mathrm{C}$ except for E. coli which was maintained at $37^{\circ} \mathrm{C}$.

\section{Preparation of extracts}

Three $6 \mathrm{~mm}$ discs of the mushroom cultures from their respective agar plates were used to inoculate $1000 \mathrm{ml}$ Erlenmeyer flask containing $300 \mathrm{ml}$ of Potato Dextrose broth in triplicate and incubated under shaking at $28{ }^{\circ} \mathrm{C}$ at $180 \mathrm{rpm}$ for $21 \mathrm{~d}$. After the completion of the incubation period, the mycelia were separated from the broth aseptically using a sieve (BSS 500 micron) and airdried. The mycelia were extracted with methanol $(50 \mathrm{ml})$ in a shaker for $24 \mathrm{~h}$ at $200 \mathrm{rpm}$. The extracts were filtered through Buckner funnel assembly and were washed twice with $25 \mathrm{ml}$ methanol each. The extracts were collected and concentrated using a rotary vacuum evaporator at $45{ }^{\circ} \mathrm{C}$. The broth samples were extracted with $100 \mathrm{ml}$ ethyl acetate using liquid-liquid partitioning in a 2 liter separating funnel. The samples were further extracted two more times with $50 \mathrm{ml}$ of ethyl acetate each. All the extracts were collected and concentrated using a rotary vacuum evaporator set at $45^{\circ} \mathrm{C}$. The concentrated crude extracts were then used for bioassay studies.

Table 1: Macrofungi and corresponding codes for the extracts

\begin{tabular}{|c|c|c|c|c|}
\hline Microorganism & MTCC Number & Solvent & Extract & Fungal Code \\
\hline Flammulina velutipes (FV) & 543 & Ethyl acetate & Broth & V1B \\
\hline Flammulina velutipes (FV) & & Methanol & Mycelia & V1M \\
\hline Pleurotus florida (PF) & 9194 & Ethyl acetate & Broth & F1B \\
\hline Pleurotus florida (PF) & & Methanol & Mycelia & $\mathrm{F} 1 \mathrm{M}$ \\
\hline Pleurotus ostreatus (PO-S1) & 1801 & Ethyl acetate & Broth & $01 \mathrm{~B}$ \\
\hline Pleurotus ostreatus (PO-S1) & & Methanol & Mycelia & $01 \mathrm{M}$ \\
\hline Pleurotus ostreatus (PO-S2) & 1802 & Ethyl acetate & Broth & O2B \\
\hline Pleurotus ostreatus (PO-S2) & & Methanol & Mycelia & $02 \mathrm{M}$ \\
\hline Pleurotus sajor caju (PSC) & 141 & Ethyl acetate & Broth & C1B \\
\hline Pleurotus sajor caju (PSC) & & Methanol & Mycelia & $\mathrm{C} 1 \mathrm{M}$ \\
\hline TERI-G1 (TG-1) & & Ethyl acetate & Broth & $\mathrm{T} 1 \mathrm{~B}$ \\
\hline TERI-G1 (TG-1) & & Methanol & Mycelia & $\mathrm{T} 1 \mathrm{M}$ \\
\hline TERI-G2 (TG-2) & & Ethyl acetate & Broth & $\mathrm{T} 2 \mathrm{~B}$ \\
\hline TERI-G2 (TG-2) & & Methanol & Mycelia & $\mathrm{T} 2 \mathrm{M}$ \\
\hline TERI-G3 (TG-3) & & Ethyl acetate & Broth & T3B \\
\hline TERI-G3 (TG-3) & & Methanol & Mycelia & T3M \\
\hline TERI-G4 (TG-4) & & Ethyl acetate & Broth & $\mathrm{T} 4 \mathrm{~B}$ \\
\hline TERI-G4 (TG-4) & & Methanol & Mycelia & $\mathrm{T} 4 \mathrm{M}$ \\
\hline TERI-G5 (TG-5) & & Ethyl acetate & Broth & T5B \\
\hline
\end{tabular}

\section{In vitro antimicrobial study}

Agar well-diffusion method described by Perez et al. [16] was used to determine the antimicrobial activity. Mueller Hinton agar no. 2 was prepared and cooled to $40-45{ }^{\circ} \mathrm{C}$ and the bacterial inoculum $\left(1.5 \times 10^{8} \mathrm{CFU} . \mathrm{ml}^{-1}, 0.5 \mathrm{McF}\right.$ arland) prepared above was then added aseptically to the molten agar and poured into sterile petri dishes to give a solid plate. Wells ( $6 \mathrm{~mm}$ diameter) were made in each of these plates using a sterile cork borer. The wells were filled with $50 \mu \mathrm{l}$ of test extract $\left(5 \mu \mathrm{g} . \mathrm{ml}^{-1}\right)$. The plates were first incubated at $4{ }^{\circ} \mathrm{C}$ for 15 $\min$ and then at $37{ }^{\circ} \mathrm{C}$ for $18 \mathrm{~h}$ under aerobic conditions. The antimicrobial activity of the extract was determined by calculating the zone of inhibition. The diameters of zones of inhibition (ZOI) produced by the test were recorded and compared with those produced by positive control (Tetracycline at $5 \mu \mathrm{g}$. $\mathrm{ml}^{-1}$, SigmaAldrich). For negative control, pure solvent (autoclaved Milli- $Q$ water) was used in place of the extract. The experiment was performed two times in triplicates to minimize error and to check the reproducibility of results. The average values were recorded. The $\%$ antimicrobial activity was calculated with equation 1 .

$$
\% \text { Inhibition }=100-\left\{\frac{[\text { (ZOI control-ZoI sample })]}{\text { (ZOI control) }} * 100\right\} \text { Equation } 1
$$

\section{Sun protection factor}

SPF determination was performed as described in Mansur et al. 1986 [17]. Absorbance readings of the crude extracts $\left(200 \mu \mathrm{g}\right.$. $\mathrm{ml}^{-1}$ concentration) dissolved in ethanol were taken in the wavelength range of 290 to $320 \mathrm{~nm}$ at $5 \mathrm{~nm}$ interval. A dilution to $100 \mu \mathrm{g}$. ml-1 was done with crude extracts showing exceeding spectroscopic readings. Mansur equation as mentioned in equation 2 was used to determine the SPF values of the crude extracts.

$$
\mathrm{SPF}=\mathrm{CF} \times \sum_{290}^{320} \mathrm{EE}(\lambda) \times \mathrm{I}(\lambda) \times \operatorname{Abs}(\lambda) \ldots \text { Equation } 2
$$

where CF is 10 (correction factor), EE $(\lambda)$ is erythemogenic effect of radiation at wavelength $\lambda, I(\lambda)$ is the intensity of solar light at wavelength $\lambda$, and abs $(\lambda)$ is the absorbance of wavelength $\lambda$ by a solution of the preparation. The obtained absorbance values were multiplied by the EE $(\lambda)$ values; their summation was taken and multiplied by the correction factor 10 .

\section{Antioxidant assay}

Antioxidant activity of the crude extracts was determined as described by Clarke et al. 2013 [18] with slight modification. 1,1Diphenyl-2-picrylhydrazyl (DPPH) free radical scavenging activity was assessed with $20 \mathrm{ul}$ of crude extract of $5000 \mu \mathrm{g}$. ml-1 concentration dissolved in methanol, mixed with $0.1 \mathrm{mmol}$ of DPPH followed by incubation in the dark for $30 \mathrm{~min}$. Absorption was taken at $517 \mathrm{~nm}$ with the help of a UV-Visible Spectrophotometer. Appropriate blank (methanol) and positive control (Ascorbic acid and Quercetin) were used. The inhibition of the DPPH free radical in percentage (I \%) was calculated following equation 3.

$$
\% \text { Inhibition }=\left\{\frac{[\text { A control }- \text { A sample })]}{(\text { A control })} * 100\right\} \ldots . \text { Equation } 3
$$

Where $\mathrm{A}_{\text {control }}$ is the absorbance of the control reaction (full reaction, without the tested extract or Quercetin) and Asample was the absorbance 
in the presence of the sample. A fresh solution of DPPH was prepared before each experiment. Decreased absorbance of the reaction mixture indicates stronger DPPH free radical-scavenging activity. The minimum inhibitory concentration (MIC) values of the extracts showing good antioxidant properties were evaluated using the two-fold serial dilution method [19]. The samples were dissolved in methanol to obtain $5 \mathrm{mg}$. $\mathrm{ml}^{-1}$ stock solutions. With the help of serial dilution concentrations 500 $\mu \mathrm{g}$. $\mathrm{ml}^{-1}, 250 \mu \mathrm{g}$. ml-1 and $125 \mu \mathrm{g}$. $\mathrm{ml}^{-1}$ were achieved and readings were taken at $517 \mathrm{~nm}$ wavelength.

\section{Total phenolics content}

The total phenolic content (TPC) was determined calorimetrically using a Folin-Ciocalteu 96-well microplate assay as described by Zhang et al. (2006) [20]. The total phenolic content was calculated from the linear equation of a standard calibration curve prepared with gallic acid and expressed as Gallic Acid Equivalent (GAE) per gram of extract.

\section{Statistical analysis}

All data are presented as mean \pm standard error of the means (SEM). Data for antimicrobial studies were analyzed using a 2way analysis of variance (ANOVA) using GraphPad Prism version 8.0.2. Differences were accepted as statistically significant when $p$-value $<0.05$.

\section{RESULTS AND DISCUSSION}

\section{Antimicrobial studies}

Continued search for antibacterial activity assessment of new potential active ingredients is crucial as gram-positive $(S$. epidermidis, M. luteus, B. megaterium, $S$. aureus) and gram-negative (E. coli, P. aeruginosa, A. baumannii) bacteria considered for this study are associated with systemic infections namely, urinary tract infections, respiratory system infections, dermatitis, soft tissue infections, bacteremia, bone and joint infections, gastrointestinal infections and has been reported to have developed resistance against several commercial antibiotics [21]. As enumerated in table 2, extracts displayed different levels of antibacterial activities against the tested pathogenic bacteria. Broth culture of P. florida and TERI-G1 showed a broad-spectrum antibacterial activity against $S$. epidermidis, E. coli, M. luteus, B. megaterium cultures, with $P$. florida showing specific activity against $P$. aeruginosa and TERI-G1 against $A$. baumannii and $S$. aureus. Antibacterial activity as observed in remaining extracts was negligible or less than $50 \%$ relative to tetracycline, the positive control taken in the study. The antimicrobial activity of fungal extracts against different bacteria was found to be significant during statistical analysis (p-value $<0.05)$.

Table 2: Antibacterial activities of the crude fungal extracts

\begin{tabular}{|c|c|c|c|c|c|c|c|}
\hline \multirow{2}{*}{$\begin{array}{l}\text { Fungal } \\
\text { code }\end{array}$} & \multicolumn{7}{|c|}{ Antibacterial activity (\%)* } \\
\hline & S. epidermidis & E. coli & M. luteus & B. megaterium & P. aeruginosa & A. baumannii & S. aureus \\
\hline V1B & $0.00 \pm 0.00$ & $0.00 \pm 0.00$ & $28.41 \pm 1.14$ & $40.00 \pm 3.64$ & $41.18 \pm 1.96$ & $0.00 \pm 0.00$ & $0.00 \pm 0.00$ \\
\hline V1M & $0.00 \pm 0.00$ & $0.00 \pm 0.00$ & $0.00 \pm 0.00$ & $0.00 \pm 0.00$ & $39.22 \pm 3.92$ & $0.00 \pm 0.00$ & $0.00 \pm 0.00$ \\
\hline F1B & $21.51 \pm 0.00$ & $26.67 \pm 0.00$ & $22.73 \pm 0.0$ & $45.45 \pm 1.82$ & $43.14 \pm 3.92$ & $0.00 \pm 0.00$ & $0.00 \pm 0.00$ \\
\hline F1M & $0.00 \pm 0.00$ & $0.00 \pm 0.00$ & $0.00 \pm 0.00$ & $0.00 \pm 0.00$ & $43.14 \pm 3.92$ & $0.00 \pm 0.00$ & $0.00 \pm 0.00$ \\
\hline 01B & $0.00 \pm 0.00$ & $0.00 \pm 0.00$ & $0.00 \pm 0.00$ & $34.55 \pm 1.82$ & $43.14 \pm 3.92$ & $0.00 \pm 0.00$ & $0.00 \pm 0.00$ \\
\hline $01 \mathrm{M}$ & $0.00 \pm 0.00$ & $0.00 \pm 0.00$ & $0.00 \pm 0.00$ & $60.00 \pm 5.45$ & $39.22 \pm 0.00$ & $0.00 \pm 0.00$ & $0.00 \pm 0.00$ \\
\hline O2B & $0.00 \pm 0.00$ & $0.00 \pm 0.00$ & $22.73 \pm 0.00$ & $36.36 \pm 0.00$ & $35.29 \pm 3.92$ & $0.00 \pm 0.00$ & $0.00 \pm 0.00$ \\
\hline $\mathrm{O} 2 \mathrm{M}$ & $0.00 \pm 0.00$ & $0.00 \pm 0.00$ & $0.00 \pm 0.00$ & $32.73 \pm 3.64$ & $41.18 \pm 1.96$ & $0.00 \pm 0.00$ & $0.00 \pm 0.00$ \\
\hline C1B & $0.00 \pm 0.00$ & $0.00 \pm 0.00$ & $0.00 \pm 0.00$ & $49.09 \pm 5.45$ & $47.06 \pm 3.92$ & $0.00 \pm 0.00$ & $0.00 \pm 0.00$ \\
\hline C1M & $0.00 \pm 0.00$ & $0.00 \pm 0.00$ & $0.00 \pm 0.00$ & $0.00 \pm 0.00$ & $39.22 \pm 0.00$ & $0.00 \pm 0.00$ & $0.00 \pm 0.00$ \\
\hline $\mathrm{T} 1 \mathrm{~B}$ & $50 \pm 0.00$ & $51.28 \pm 0.00$ & $44.44 \pm 0.00$ & $56.86 \pm 9.8$ & $0.00 \pm 0.00$ & $33.85 \pm 3.08$ & $64.79 \pm 5.63$ \\
\hline $\mathrm{T} 1 \mathrm{M}$ & $21.43 \pm 0.00$ & $0.00 \pm 0.00$ & $25.56 \pm 1.11$ & $56.86 \pm 9.8$ & $0.00 \pm 0.00$ & $0.00 \pm 0.00$ & $50.7 \pm 0.00$ \\
\hline $\mathrm{T} 2 \mathrm{~B}$ & $0.00 \pm 0.00$ & $0.00 \pm 0.00$ & $0.00 \pm 0.00$ & $0.00 \pm 0.00$ & $0.00 \pm 0.00$ & $0.00 \pm 0.00$ & $0.00 \pm 0.00$ \\
\hline $\mathrm{T} 2 \mathrm{M}$ & $0.00 \pm 0.00$ & $0.00 \pm 0.00$ & $0.00 \pm 0.00$ & $0.00 \pm 0.00$ & $0.00 \pm 0.00$ & $0.00 \pm 0.00$ & $0.00 \pm 0.00$ \\
\hline T3B & $0.00 \pm 0.00$ & $51.28 \pm 0.00$ & $27.78 \pm 1.11$ & $35.29 \pm 3.92$ & $0.00 \pm 0.00$ & $0.00 \pm 0.00$ & $0.00 \pm 0.00$ \\
\hline T3M & $0.00 \pm 0.00$ & $0.00 \pm 0.00$ & $0.00 \pm 0.00$ & $0.00 \pm 0.00$ & $0.00 \pm 0.00$ & $0.00 \pm 0.00$ & $0.00 \pm 0.00$ \\
\hline $\mathrm{T} 4 \mathrm{~B}$ & $0.00 \pm 0.00$ & $69.23 \pm 7.69$ & $28.89 \pm 2.22$ & $35.29 \pm 3.92$ & $0.00 \pm 0.00$ & $0.00 \pm 0.00$ & $26.76 \pm 1.41$ \\
\hline $\mathrm{T} 4 \mathrm{M}$ & $0.00 \pm 0.00$ & $51.28 \pm 0.00$ & $27.78 \pm 1.11$ & $35.29 \pm 3.92$ & $0.00 \pm 0.00$ & $0.00 \pm 0.00$ & $0.00 \pm 0.00$ \\
\hline T5B & $0.00 \pm 0.00$ & $61.54 \pm 0.00$ & $35.56 \pm 2.22$ & $35.29 \pm 3.92$ & $0.00 \pm 0.00$ & $0.00 \pm 0.00$ & $25.35 \pm 2.82$ \\
\hline
\end{tabular}

The $\%$ antimicrobial activity was calculated using equation 1 and expressed as a mean \pm standard deviation to the mean. (n=3)*(Data was found to be significant, $\mathrm{p}<0.05$ ).

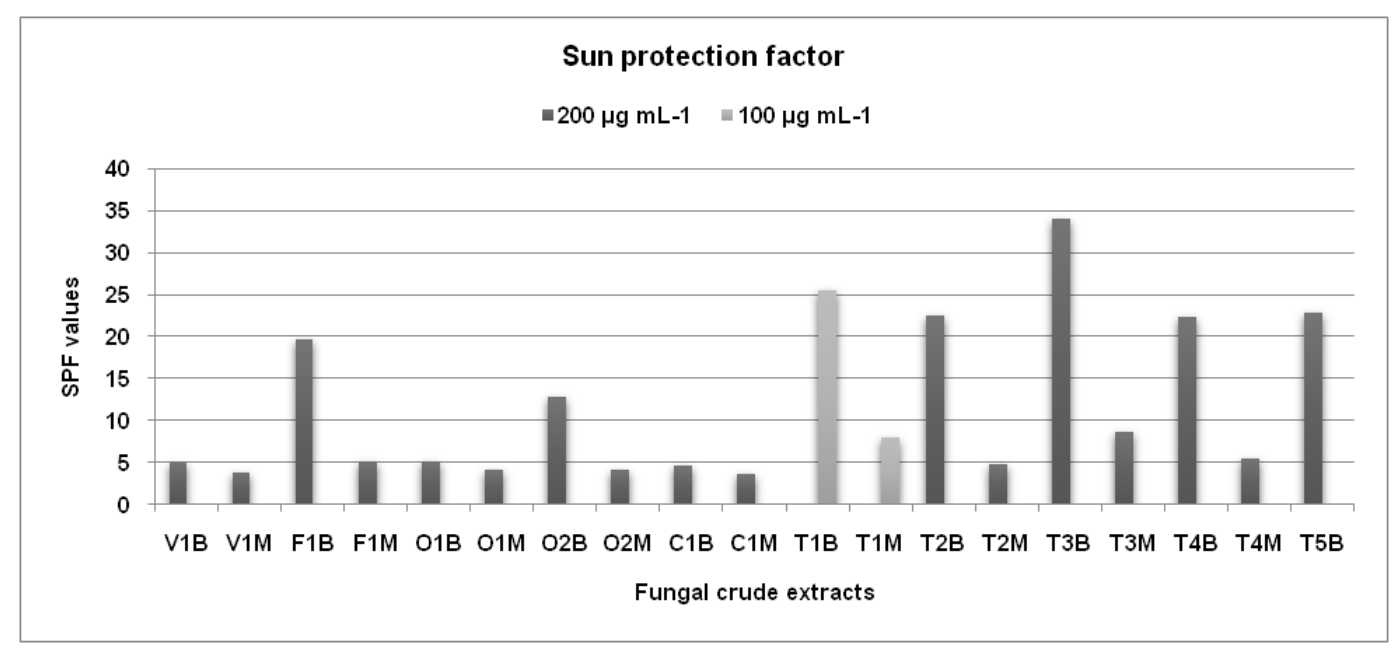

Fig. 1: Sun protection factor of the fungal extracts, SPF values were calculated using Mansur equation (equation 2) and expressed in fig. 1. $(n=1)$ 


\section{Sun protection factor}

Calculated values of SPF of the crude extracts isolated from the selected macrofungi were found to be in the range of 3.67-34.02. Dutra et al. (2004) [22] analyzed several commercial products containing a combination of active ingredients viz., benzophenone-3, octyl methoxycinnamate and octyl salicylate (in varying proportions) for their SPF values and compared them with the declared values in their product label and found to be in the range of 15-20. In the present study, crude extracts of TERI-G3 (T3B) showed promising SPF activity of 34.02 at $200 \mu \mathrm{g}$. $\mathrm{ml}^{-1}$. P. florida (F1B), TERIG1 (T1B), TERI-G2 (T2B), TERI-G4 (T4B) and TERI-G5 (T5B) also showed comparable SPF of 19.63, 25.50, 22.44, 22.31 and 22.87 respectively.

\section{Antioxidant activity}

Ascorbic acid and Quercetin were used as a positive control in this study which showed as $85.83 \%$ and $83.09 \%$ DPPH free radical scavenging activity respectively. Broth of $P$. florida, F. velutipes, $P$. ostreatus, TERI-G1 showed comparable scavenging activity as positive control with values of $79.51,66.8,82.02$ and $69.58 \%$ respectively. Broth of P. florida, F. velutipes, P. ostreatus and TERIG1-B showed MIC at 1250, 3552.89, 2418.9 and $3219 \mu \mathrm{g} . \mathrm{ml}^{-1}$ Mycelia of $P$. florida showed MIC at $2903.76 \mu \mathrm{g} . \mathrm{ml}^{-1}$.

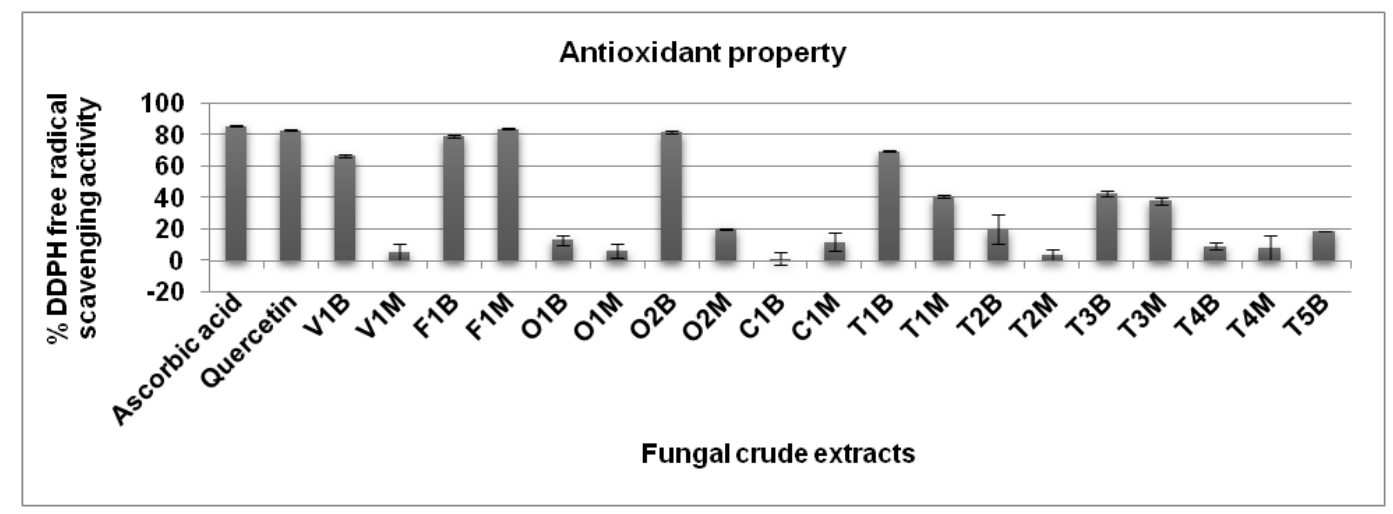

Fig. 2: DPPH free radical scavenging activity of the fungal extracts, the \% antioxidant activity was calculated using equation 3 and expressed as mean \pm standard error to the mean $(n=2)$

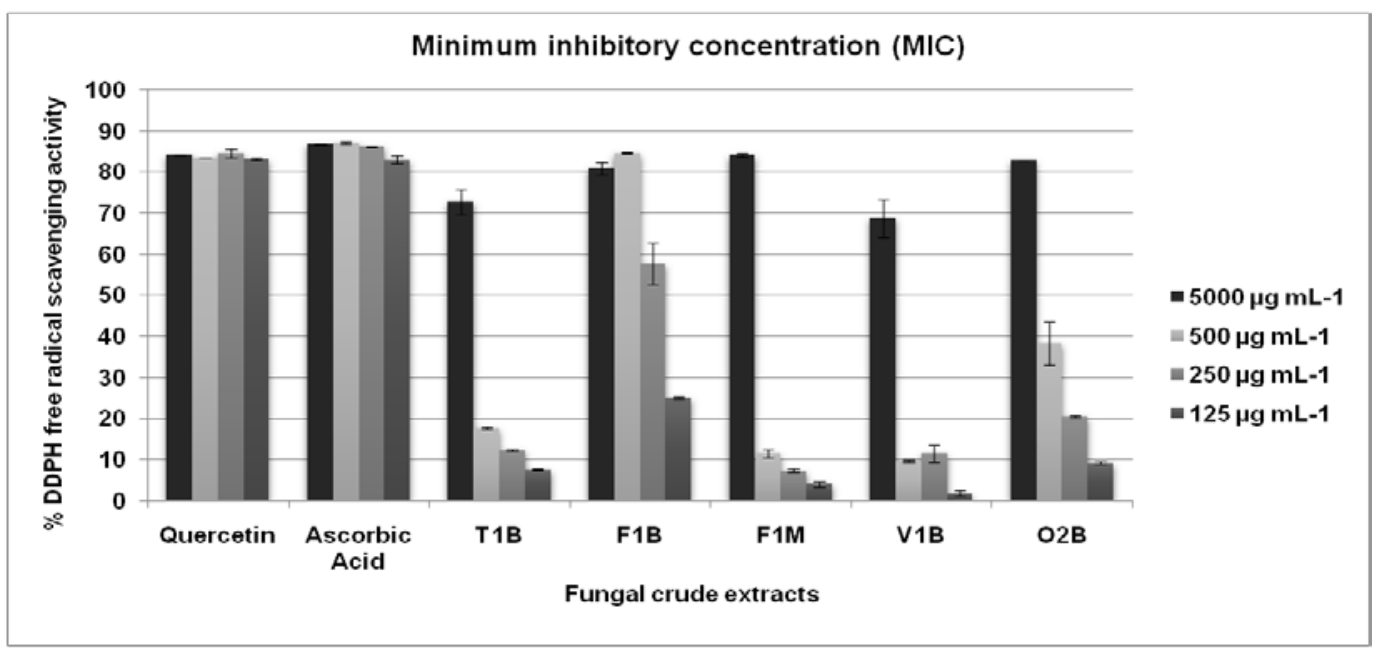

Fig. 3: Minimum inhibitory concentration of the selected fungal extracts, the MIC values are expressed as mean \pm standard error to the mean $(n=2)$

\section{Total phenolic content}

Phenolic compounds have been well documented for their contribution to antioxidant activity. These compounds are good electron donors, which directly contribute to antioxidant action [23]. Some phenolic compounds also stimulate the synthesis of endogenous antioxidant molecules in the cell [24]. Therefore, knowledge of total phenolic content is necessary for our study. Broth of $P$. florida, F. velutipes, $P$. ostreatus and TERI-G1-B showed total phenolics content of 43.68, 6.93, 20.88 and 13.77 gallic acid equivalent (GAE) per gram. Mycelia of $P$. florida showed a total phenolics content of 5.96 gallic acid equivalent (GAE) per gram.

Table 3: Total phenolic contents of the selected crude fungal extracts

\begin{tabular}{ll}
\hline Extract code & Total phenolics content (Gallic acid equivalent (GAE) per gram) \\
\hline T1B & $13.77 \pm$ \\
F1B & $43.68 \pm$ \\
F1M & $05.96 \pm$ \\
V1B & $06.93 \pm$ \\
O2B & $20.88 \pm$ \\
\hline
\end{tabular}

Total phenolic content was plotted from a standard curve of Gallic acid equivalent. $(\mathrm{n}=2)$ 


\section{CONCLUSION}

The most promising activity was shown by TERI G1, TERI G3, and $P$. florida extracts. The work is in progress to identify and characterize TERI-G1and TERI G3 cultures. Further studies on the antiinflammatory, anti-tyrosinase, elastase inhibition properties of the cultures will be assessed to identify potential cosmeceutical active ingredients with promising applications in cosmeceutical products.

\section{ACKNOWLEDGMENT}

We thank The Director, Sustainable Agriculture Division, TD-NBC, TERI, India for providing necessary facilities to carry out research work.

\section{AUTHORS CONTRIBUTIONS}

All authors contributed extensively to the work presented in this paper.

\section{CONFLICT OF INTERESTS}

The authors declared no conflict of interest.

\section{REFERENCES}

1. Brandt FS, Cazzaniga A, Hann M. Cosmeceuticals: current trends and market analysis. Semin Cutaneous Med Surg 2011;30:141-3.

2. Mukta S, Adam F. Cosmeceuticals in day-to-day clinical practice. J Drugs Dermatol 2010;9:s62-6.

3. Camassola M. Mushrooms-the incredible factory for enzymes and metabolites productions. Ferment Technol 2013;2:1.

4. Wu Y, Choi MH, Li J, Yang H, Shin HJ. Mushroom cosmetics: the present and future. Cosmetics 2016;3:22

5. Jandaik S, Anjana S. Oyster mushroom: an answer to human ailments: a review. Asian J Pharm Clin Res 2017;10:24-7.

6. Chandran PK, Ulagan MP. Antimicrobial and anticancer activity of silver nanoparticles from edible mushroom: a review. Asian J Pharm Clin Res 2017;10:37-40.

7. Jikai L. Biologically active substances from mushrooms in Yunnan, China. Heterocycles 2002;57:157-67.

8. Zhang Y, Mills GL, Nair MG. Cyclooxygenase inhibitory and antioxidant compounds from the mycelia of the edible mushroom Grifola frondosa. J Agric Food Chem 2002; 50:7581-5.

9. Choi MH, Han HK, Lee YJ, Jo HG, Shin HJ. In vitro anticancer activity of hydrophobic fractions of Sparassis latifolia extract using AGS, A529, and HepG2 cell lines. J Mushroom 2014;12:304-10.

10. Van Griensven LJLD. Culinary-medicinal mushrooms: must action be taken? Int J Med Mushrooms 2009;11:281.
11. Bilal AW, Bodha RH, Wani AH. Nutritional and medicinal importance of mushrooms. J Med Plants Res 2010;4:2598-604.

12. Wasser SP. Medicinal mushroom science: history, current status, future trends, and unsolved problems. Int J Med Mushrooms 2010;12:1.

13. Alves MJ, Ferreira ICFR, Dias J, Teixeira V, Martins A, Pintado M. A review on antimicrobial activity of mushroom (basidiomycetes) extracts and isolated compounds. Planta Med 2012;78:1707-18.

14. Heleno SA, Martins A, Queiroz MJRP, Ferreira ICFR. Bioactivity of phenolic acids: metabolites versus parent compounds: a review. Food Chem 2015;173:501-13.

15. Hyde KD, Bahkali AH, Moslem MA. Fungi-an unusual source for cosmetics. Fungal Diversity 2010;43:1-9.

16. Perez C, Paul M, Bazerque P. Antibiotic assay by agar well diffusion method. Acta Biol Med Exp 1990;15:113-5.

17. Mansur JS, Breder MNR, Mansur MCA, Azulay RD. Determination of sun protection factor by spectrophotometry. An Bras Dermatol 1986;61:121-4.

18. Clarke G, Ting KN, Wiart C, Fry J. High correlation of 2,2diphenyl-1-picrylhydrazyl (DPPH) radical scavenging, ferric reducing activity potential, and total phenolics content indicates redundancy in use of all three assays to screen for antioxidant activity of extracts of plants from the malaysian rainforest. Antioxidants 2013;2:1-10.

19. Siddiqi R, Naz S, Ahmad S, Sayeed SA. Antimicrobial activity of the polyphenolic fractions derived from Grewia asiatica, Eugenia jambolana and Carissa carandas. Int J Food Sci Technol 2011;46:250-6.

20. Zhang Q, Zhang J, Shen J, Silva A, Dennis DA, Barrow CJ. A simple 96-well microplate method for estimation of total polyphenol content in seaweeds. J Appl Phycol 2006;18:445-50.

21. Gandra S, Mojica N, Klein EY, Ashok A, Nerurkar V, Kumari M, et al. Trends in antibiotic resistance among major bacteria pathogens isolated from blood cultures tested at a large private laboratory network in India, 2008-2014. Int J Infect Dis 2016;50:75-82.

22. Dutra EA, da Costa Oliveira DAG, Kedor Hackmann ERM, Maria Ines Rocha. Determination of sun protection factor (SPF) of sunscreens by ultraviolet spectrophotometry. Rev Bras Cienc Farm 2004;40:381-5.

23. Bendary E, Francis RR, Ali HMG, Sarwat MI, El Hady S. Antioxidant and structure-activity relationships (SARs) of some phenolic and anilines compounds. Ann Agric Sci 2013;58:173-81.

24. Aryal S, Baniya MK, Danekhu K, Kunwar P, Gurung R, Koirala N. Total phenolic content, flavonoid content and antioxidant potential of wild vegetables from western Nepal. Plants 2019;8:96. 